\title{
Visfatin regulates insulin secretion, insulin receptor signalling and mRNA expression of diabetes-related genes in mouse pancreatic $\beta$-cells
}

\author{
James E P Brown, David J Onyango², Manjunath Ramanjaneya', Alex C Conner ${ }^{1}$, \\ Snehal T Patel ${ }^{1}$, Simon J Dunmore ${ }^{2}$ and Harpal S Randeva ${ }^{1}$ \\ School of Life and Health Sciences, Aston Research Centre for Healthy Ageing, Aston University, Birmingham B4 7ET, UK \\ ${ }^{1}$ Endocrinology and Metabolism Research Group, Warwick Medical School, University of Warwick, Coventry CV4 7AL, UK \\ ${ }^{2}$ Diabetes and Metabolic Disorders Research Group, Research Institute in Healthcare Sciences, University of Wolverhampton, Wulfruna Street, Wolverhampton WV1 1SB, UK \\ (Correspondence should be addressed to H S Randeva; Email: hrandeva@ bio.warwick.ac.uk)
}

\begin{abstract}
The role of the adipocyte-derived factor visfatin in metabolism remains controversial, although some pancreatic $\beta$-cellspecific effects have been reported. This study investigated the effects of visfatin upon insulin secretion, insulin receptor activation and mRNA expression of key diabetes-related genes in clonal mouse pancreatic $\beta$-cells. $\beta$-TC 6 cells were cultured in RPMI 1640 and were subsequently treated with recombinant visfatin. One-hour static insulin secretion was measured by ELISA. Phospho-specific ELISA and western blotting were used to detect insulin receptor activation. Real-time SYBR Green PCR array technology was used to measure the expression of 84 diabetes-related genes in both treatment and control cells. Incubation with visfatin caused significant changes in the mRNA expression of several key diabetes-related genes, including marked up-regulation of insulin (9-fold increase), hepatocyte nuclear factor (HNF)1 $\beta$ (32-fold increase), HNF4 $\alpha$ (16-fold increase) and nuclear factor $\kappa B$ (40-fold increase). Significant down-regulation was seen in angiotensin-converting enzyme (-3.73-fold) and UCP2 (-1.3-fold). Visfatin also caused a significant $46 \%$ increase in insulin secretion compared to control $(P<0.003)$ at low glucose, and this increase was blocked by co-incubation with the specific nicotinamide phosphoribosyltransferase inhibitor FK866. Both visfatin and nicotinamide mononucleotide induced activation of both insulin receptor and extracellular signal-regulated kinase (ERK)1/2, with visfatin-induced insulin receptor/ERK1/2 activation being inhibited by FK866. We conclude that visfatin can significantly regulate insulin secretion, insulin receptor phosphorylation and intracellular signalling and the expression of a number of $\beta$-cell function-associated genes in mouse $\beta$-cells.
\end{abstract}

Journal of Molecular Endocrinology (2010) 44, 171-178

\section{Introduction}

Type 2 diabetes (T2D) is a condition with a multifactorial aetiology. Obesity is one well-established risk factor for $\mathrm{T} 2 \mathrm{D}$, with the prevalence of obesity being $>90 \%$ in sufferers of T2D in some western societies (Astrup \& Finer 2000). Although the precise mechanisms by which increased adiposity predisposes so strongly for T2D are not fully understood, one emerging paradigm is an involvement of adipose tissue-secreted molecules commonly referred to as adipokines. These molecules include hormones, growth factors and cytokines such as resistin, visfatin, adiponectin, retinol-binding protein 4, leptin and tumour necrosis factor- $\alpha$ (Ahima 2006), which have been implicated in the modulation of both insulin sensitivity and $\beta$-cell function (Brown et al. 2002, 2007, Trayhurn \& Wood 2005). Research has shown that the majority of these molecules circulate in increased concentrations in obese individuals.
One of the more recently described adipokines is visfatin (Berndt et al. 2005). Visfatin (also referred to as pre-B cell colony-enhancing factor) was initially reported as having insulin-mimetic properties. Subsequent studies have identified visfatin as a nicotinamide phosphoribosyltransferase (NAMPT) capable of producing nicotinamide mononucleotide (NMN), a precursor for the metabolic co-factor $\mathrm{NAD}^{+}$(Kim et al. 2006). The circulating levels of visfatin have been reported to be elevated in both obesity and T2D (Li et al. 2006, Jin et al. 2008), suggesting that in these metabolic disorders, the pancreatic $\beta$-cell may be exposed to elevated visfatin levels. As the pancreatic $\beta$-cell is known to express the insulin receptor (Muller et al. 2006) and the insulin receptor is known to have an essential role in regulating $\beta$-cell function (Otani et al. 2004), any compound such as visfatin which may interact with insulin signalling could potentially elicit significant regulatory effects.

DOI: 10.1677/JME-09-0071 Online version via http://www.endocrinology-journals.org 
Interestingly, previous studies have given conflicting results regarding a role for visfatin in the $\beta$-cell with visfatin being reported to be not only a positive regulator of pancreatic $\beta$-cell function (Revollo et al. 2007) but also a negative one (Lopez-Bermejo et al. 2006), suggesting that the role of visfatin in diabetes is yet to be clearly elucidated.

This study therefore aimed to clarify the actions of visfatin in the pancreatic $\beta$-cell by investigating not only its effects on insulin secretion and insulin receptor phosphorylation, but also its regulation of the expression of a panel of diabetes-related genes in mouse pancreatic $\beta$-cells.

\section{Materials and methods}

\section{Cell culture and treatment}

All materials were purchased from Sigma unless otherwise stated.

$\beta$-TC6 cell line (BTC) cells were purchased from ATCC (LGC Promochem, Teddington, UK). Cells between passages 30-38 were cultured in standard $11 \mathrm{mmol} / 1$ glucose RPMI-1640 (supplemented with $2 \mathrm{mmol} / \mathrm{l}$ L-glutamine, $50 \mathrm{IU} / \mathrm{ml}$ penicillin and $50 \mu \mathrm{g} / \mathrm{ml}$ streptomycin, and $10 \%$ foetal bovine serum) prior to treatment.

For experimental treatments, cells were seeded into 6-well plates (gene and protein expression) or in 96-well plates (for insulin secretion, extracellular signalregulated kinase (ERK) $1 / 2$ activation and cell viability assays). Cells were serum starved for $4 \mathrm{~h}$ and were subsequently incubated with serum-free RPMI containing either recombinant visfatin (Axxora, Nottingham, UK) NMN, U0126 (Promega) or FK866 (AxonChem Groningen, Netherlands) for appropriate time courses.

\section{PCR array analysis and real-time PCR}

For gene expression experiments, total RNA was extracted using SV Total RNA Isolation kit (Promega). RNA was DNase treated and $1 \mu \mathrm{g}$ total RNA was reverse transcribed using a first-strand cDNA synthesis kit (PrimerDesign, Southampton, UK). Ninety-eight microlitres of the resulting cDNA were mixed with $1225 \mu \mathrm{l}$ of SYBR Green PCR master mix (PrimerDesign) and $1127 \mu \mathrm{l}$ of PCR water (Ambion, Warrington, UK) and were aliquoted out into a commercially available diabetes pathway-specific real-time PCR array (Tebu-Biosciences, Peterborough, UK). Samples were run as duplicates for 40 cycles using an iCycler thermal cycler (Bio-Rad). Cycle thresholds were measured, and the relative expression of genes was calculated by comparison of $C_{\mathrm{t}}$ values. The mean for all samples was calculated and subsequently normalized to the housekeeping genes $\beta$-glucoronidase, hypoxanthine phosphoribosyltransferase 1 , heat shock $90 \mathrm{kDa}$ protein $1 \beta, \beta$-actin and glyceraldehydes-3-phosphate dehydrogenase. Melt-curve analysis was used to confirm single amplicon production for each gene tested. Genomic contamination was assessed by non-reverse transcribed samples (RT-ve). Pre-validated SYBR Green PCR primers (PrimerDesign) were used to confirm PCR array results in a separate set of experiments (Supplementary Figure 1, see section on supplementary data given at the end of this article).

\section{Insulin secretion}

Cells were treated with a dose range $(0-200 \mathrm{ng} / \mathrm{ml})$ of visfatin for $1 \mathrm{~h}$. Supernatants were collected and centrifuged to remove any cells, and insulin content was measured using a mouse insulin ELISA kit (Mercodia, Uppsala, Sweden).

\section{Insulin receptor activation}

To measure the effect of visfatin on insulin receptor activation, sandwich ELISA using phospho-specific anti-insulin receptor antibodies was employed (R\&D, Abingdon, UK). Phospho-specific western blotting was used to qualitatively confirm the results. Cells were cultured as described above and were treated with visfatin in a concentration-dependent $(0-200 \mathrm{ng} / \mathrm{ml})$ and time-dependent $(0,2,5,15,30$ and $60 \mathrm{~min})$ manner. Cell lysates were collected using RIPA buffer containing phosphatase and protease inhibitors for assay. Insulin treatment of $100 \mathrm{nmol} / 1$ was used as a positive control for insulin receptor activation.

\section{ERK1/2 activation assay}

To study the activation of intracellular p42-44 ERK signalling, a proprietary phospho-ERK1/2 ELISA was used (RayBiotech, Norcross, GA, USA). Cells were plated out in 96-well plates and treated over a time period $(0,2,5,15,30$ and $60 \mathrm{~min})$ with $200 \mathrm{ng} / \mathrm{ml}$ visfatin before being fixed and assayed. Five-minute phorbol myristate acetate (PMA) treatment was used as a positive control for ERK1/2 activation, $n=5$.

\section{Statistical analysis}

Statistical analysis for PCR array was undertaken using a Mann-Whitney $U$ test. For insulin secretion, ERK1/2 activation and cell viability experiments, ANOVA followed by Tukey's post-hoc test was used; $P \leq 0.05$ was taken as a point of significance. 
Table 1 Visfatin regulation of $\beta$-cell mRNA expression

Fold change

$P$ value

\section{Compared to contro}

\section{Gene}

Angiotensin-converting enzyme

ATP citrate lyase

Adrenergic receptor $1 \mathrm{a}$

Adrenergic receptor $3 b$

Angiotensinogen

V-Akt murine thymoma viral oncogene homolog 2

Aquaporin 2

Chemokine ligand 5

Chemokine receptor 2

CD28

CeaCam1

CCAAT/enhancer-binding protein (C/EBP), $\alpha$

Cytotoxic T-lymphocyte-associated protein 4

Dipeptidylpeptidase 4

Dual specificity phosphatase 4

Ectonucleotide pyrophosphatase/phosphodiesterase 1

Fructose-1,6-bisphosphatase 1

Forkhead box $\mathrm{C} 2$

Forkhead box $\mathrm{G} 1$

Forkhead box P3

Glucose-6-phosphatase, catalytic subunit

Glucose-6-phosphate dehydrogenase 2

Glucagon

Glucagon receptor

Glucose transporter type 4

Glucagon-like peptide 1 receptor

Glycerol-3-phosphate dehydrogenase 1 (soluble)

Glycogen synthase kinase $3 \beta$

Heme oxygenase (decycling) 1

HNF $\beta 1$

$\mathrm{HNF} 4 \alpha$

Intercellular adhesion molecule 1

Insulin-degrading enzyme

Interferon $\gamma$

IGF-binding protein 5

Inhibitor of nuclear factor $\kappa-B$ kinase $\beta$ subunit

IL10

IL12b

IL4 receptor, $\alpha$

IL6

Inositol polyphosphate phosphatase-like 1

Insulin

Insulin receptor substrate 1

Mitogen-activated protein kinase 14

Mitogen-activated protein kinase 8

Neurogenic differentiation 1

Nuclear factor $\kappa-B$ DNA binding subunit

Nitric oxide synthase 3

Nuclear respiratory factor 1

$\mathrm{N}$-ethylmaleimide-sensitive factor

Pancreatic and duodenal homeobox 1

Poly (ADP-ribose) polymerase family member 1

Paired box gene 4

Phosphoenolpyruvate carboxykinase 1

6-Phosphofructo-2-kinase/fructose-2,6-bisphosphatase

Phosphatidylinositol-3-kinase catalytic $\delta$ polypeptide

Phosphoinositide-3-kinase, regulatory subunit $1(\alpha)$

PPAR $\alpha$

\begin{tabular}{|c|c|}
\hline$-3 \cdot 732$ & 0.019 \\
\hline $2 \cdot 701$ & 0.471 \\
\hline 4.925 & 0.518 \\
\hline $1 \cdot 231$ & 0.334 \\
\hline $1 \cdot 823$ & 0.845 \\
\hline $24 \cdot 251$ & 0.002 \\
\hline $1 \cdot 260$ & 0.338 \\
\hline $7 \cdot 294$ & 0.052 \\
\hline $3 \cdot 175$ & 0.330 \\
\hline $97 \cdot 006$ & 0.009 \\
\hline$-2 \cdot 828$ & 0.027 \\
\hline $4 \cdot 387$ & 0.407 \\
\hline 8.574 & 0.167 \\
\hline 1.097 & 0.075 \\
\hline 3.647 & 0.419 \\
\hline $1 \cdot 516$ & 0.663 \\
\hline-2.000 & 0.158 \\
\hline $1 \cdot 741$ & 0.831 \\
\hline $1 \cdot 414$ & 0.801 \\
\hline$-1 \cdot 289$ & 0.087 \\
\hline 4.925 & 0.075 \\
\hline 1.910 & 0.775 \\
\hline $1 \cdot 782$ & 0.652 \\
\hline $2 \cdot 297$ & 0.873 \\
\hline $2 \cdot 701$ & 0.624 \\
\hline 1.072 & 0.284 \\
\hline 2.962 & 0.172 \\
\hline$-1 \cdot 447$ & 0.266 \\
\hline $3 \cdot 647$ & 0.202 \\
\hline 32.000 & 0.011 \\
\hline 16.000 & 0.020 \\
\hline$-1 \cdot 260$ & 0.363 \\
\hline $1 \cdot 097$ & 0.396 \\
\hline $2 \cdot 764$ & 0.586 \\
\hline $2 \cdot 764$ & 0.844 \\
\hline 1.516 & 0.727 \\
\hline $3 \cdot 127$ & 0.482 \\
\hline $4 \cdot 812$ & 0.664 \\
\hline $12 \cdot 409$ & 0.103 \\
\hline $2 \cdot 351$ & 0.692 \\
\hline $2 \cdot 462$ & 0.371 \\
\hline 8.980 & 0.037 \\
\hline $4 \cdot 287$ & 0.320 \\
\hline $2 \cdot 639$ & 0.771 \\
\hline$-1 \cdot 122$ & 0.039 \\
\hline $1 \cdot 122$ & 0.118 \\
\hline $40 \cdot 317$ & 0.019 \\
\hline 3.980 & 0.360 \\
\hline 1.587 & 0.391 \\
\hline $2 \cdot 245$ & 0.901 \\
\hline 2.047 & 0.922 \\
\hline $1 \cdot 176$ & 0.169 \\
\hline $16 \cdot 000$ & 0.114 \\
\hline 3.482 & 0.108 \\
\hline 3.482 & 0.451 \\
\hline 2.095 & 0.967 \\
\hline $2 \cdot 297$ & 0.947 \\
\hline$-1 \cdot 260$ & 0.04 \\
\hline
\end{tabular}

(continued) 
Table 1 Continued

\section{Gene}

PPAR $\gamma$

PPAR $\gamma$, coactivator $1 \alpha$

\begin{tabular}{|c|c|}
\hline $2 \cdot 895$ & 0.762 \\
\hline $5 \cdot 528$ & 0.404 \\
\hline $2 \cdot 297$ & 0.904 \\
\hline 2.000 & 0.777 \\
\hline $1 \cdot 176$ & 0.284 \\
\hline 3.564 & 0.499 \\
\hline $15 \cdot 277$ & 0.119 \\
\hline $1 \cdot 289$ & 0.553 \\
\hline $2 \cdot 351$ & 0.874 \\
\hline$-1 \cdot 047$ & 0.417 \\
\hline$-2 \cdot 144$ & 0.128 \\
\hline $1 \cdot 414$ & 0.692 \\
\hline $1 \cdot 721$ & 0.813 \\
\hline $17 \cdot 549$ & 0.035 \\
\hline$-11 \cdot 055$ & 0.319 \\
\hline 2.962 & 0.405 \\
\hline $54 \cdot 443$ & 0.155 \\
\hline $2 \cdot 351$ & 0.891 \\
\hline $1 \cdot 662$ & 0.737 \\
\hline $2 \cdot 406$ & 0.861 \\
\hline $2 \cdot 351$ & 0.953 \\
\hline$-1 \cdot 289$ & 0.005 \\
\hline $1 \cdot 289$ & 0.331 \\
\hline$-6 \cdot 350$ & 0.307 \\
\hline$-30 \cdot 555$ & 0.254 \\
\hline$-4 \cdot 702$ & 0.390 \\
\hline
\end{tabular}

Protein tyrosine phosphatase, non-receptor type 1

Phosphorylase, glycogen, liver

RAB4A, member RAS oncogene family

Resistin

Selectin

Serine (or cysteine) peptidase inhibitor, clade E, member 1

Solute carrier family 14 (urea transporter), member 2

Synaptosome-associated protein, $23 \mathrm{kDa}$

Synaptosome-associated protein, $25 \mathrm{kDa}$

Superoxide dismutase 2

Sterol regulatory element binding transcription factor 1

Syntaxin 4

Syntaxin-binding protein 1

Syntaxin-binding protein 4

Transforming growth factor, $\beta 1$

TNF

TNF receptor superfamily, member $1 \mathrm{a}$

TNF receptor superfamily, member $1 b$

Tribbles homolog 3

Uncoupling protein 2

VAMP 2

VAMP 3

VAMP-associated protein A

Vascular endothelial growth factor $A$

SYBR Green real-time PCR array analysis of diabetes-related genes. Treatment with $50 \mathrm{ng} / \mathrm{ml}$ visfatin resulted in a significant up- or down-regulation of 12 genes compared to untreated cells. Data are representative of three independent experiments. HNF, hepatocyte nuclear factor; IL, interleukin; PPAR, peroxisome proliferator-activated receptor; TNF, tumour necrosis factor; VAMP, vesicle-associated membrane protein. Figures in bold represent statistically significant finding.

\section{Results}

\section{Visfatin regulates mRNA expression of key diabetes genes in BTC cells}

Real-time SYBR Green PCR array analysis of a diabetesspecific gene array was performed. Data analysis demonstrated that 24-h treatment of BTC cells with $50 \mathrm{ng} / \mathrm{ml}$ recombinant visfatin induced significant changes in expression (ranging from $P=0.0031$ to $P=0 \cdot 0434$ ) compared to untreated cells in 12 of the 84 genes tested (Table 1 ).

\section{Visfatin but not NMN increases insulin secretion at low glucose}

Visfatin has previously been suggested to have a role in glucose-induced insulin secretion. We therefore investigated the effect of a static 1-h incubation of BTC cells with a range of visfatin concentrations at low and high glucose levels. Incubation with $200 \mathrm{ng} / \mathrm{ml}$ visfatin for $1 \mathrm{~h}$ at $2 \cdot 2 \mathrm{mmol} / \mathrm{l}$ (low) glucose caused a significant $46 \%$ increase in insulin secretion compared to control
$(P<0 \cdot 001$; Fig. 1). Lower concentrations of visfatin $(0-100 \mathrm{ng} / \mathrm{ml})$ caused no significant change in insulin secretion. Co-incubation of visfatin with the specific NAMPT inhibitor FK866 significantly blocked the insulinotropic effect of visfatin $(P<0.05)$ compared to $200 \mathrm{ng} / \mathrm{ml}$ visfatin alone. No effect of visfatin on insulin secretion at high glucose was seen (data not shown). To investigate the involvement of ERK1/2 mitogen-activated protein kinase (MAPK) in visfatin-induced insulin secretion, cells were co-incubated with $200 \mathrm{ng} / \mathrm{ml}$ visfatin, and the ERK1/2 inhibitor U0126 and insulin secretion was measured. Co-incubation of cells with $200 \mathrm{ng} / \mathrm{ml}$ visfatin and $1 \mu \mathrm{mol} / 1 \mathrm{U} 0126$ caused no significant difference in insulinotropic effect compared with the treatment with visfatin alone. Incubation of cells with NMN alone resulted in a small non-significant increase in the levels of insulin secretion in the BTC cells $(P=0 \cdot 1)$.

\section{Incubation with visfatin induces insulin receptor phosphorylation}

Visfatin has previously been described as having the ability to activate the insulin receptor (Chan et al. 2007). 

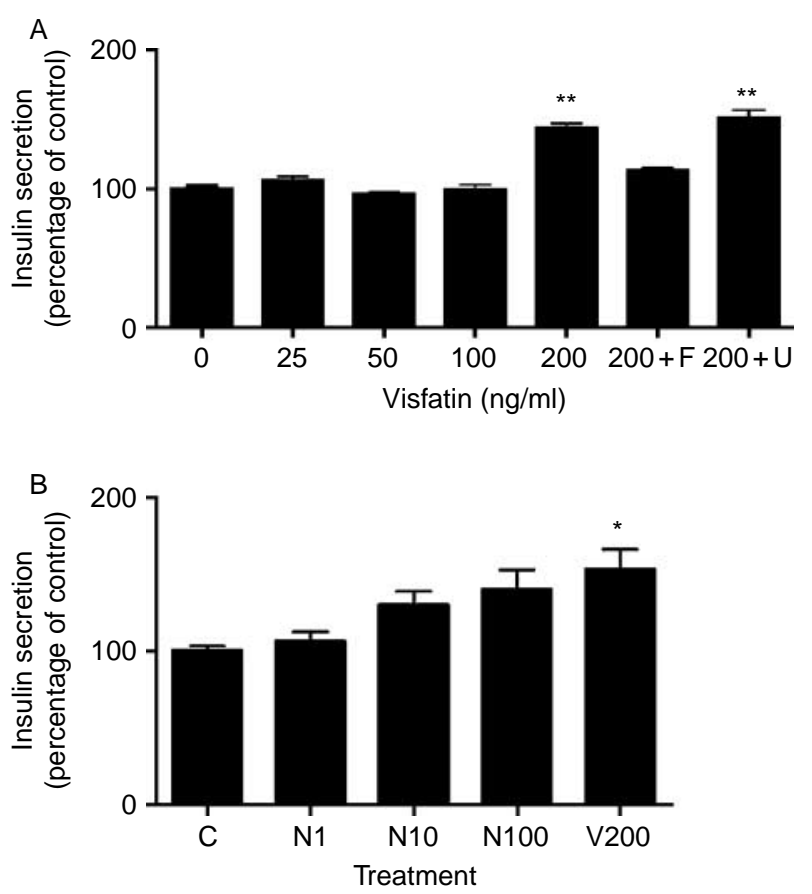

Figure 1 (A) Insulin secretion measured over 1-h static incubation. Treatment of BTC with visfatin $(200 \mathrm{ng} / \mathrm{ml})$ caused a significant increase in insulin secretion at low glucose compared to untreated cells $(P<0.01)$. Co-incubation with FK866 significantly blocked this increase in insulin secretion $(P<0 \cdot 01)$. U0126 co-incubation did not significantly alter the effects of $200 \mathrm{ng} / \mathrm{ml}$ visfatin on BTC insulin secretion compared to visfatin alone, $n=6$. (B) Incubation with 10 and $100 \mu \mathrm{M} \mathrm{NMN}$ caused a small but non-significant increase in insulin secretion at low glucose, $n=5$.

We therefore investigated the activation of the insulin receptor in BTC by visfatin. Insulin receptor activation was assessed by phospho-specific insulin receptor sandwich ELISA. Using 50, 200 and $500 \mathrm{ng} / \mathrm{ml}$ visfatin, significant increases in the level of insulin receptor phosphorylation were seen after $15 \mathrm{~min}(P<0 \cdot 001)$, with increases being greater at 200 and $500 \mathrm{ng} / \mathrm{ml}$ than at $50 \mathrm{ng} / \mathrm{ml}$. This phosphorylation decreased over the subsequent $45 \mathrm{~min}$. NMN alone also caused a significant increase in insulin receptor phosphorylation at the same time point $(P<0 \cdot 05)$. Co-incubation of cells with $200 \mathrm{ng} / \mathrm{ml}$ visfatin and the specific visfatin inhibitor FK866 caused a partial reduction in the level of insulin receptor phosphorylation compared to cells treated with $200 \mathrm{ng} / \mathrm{ml}$ visfatin alone (Fig. 2).

\section{Visfatin and NMN cause activation of ERK1/2 but not of p38 MAPK}

Visfatin has previously been shown to cause activation of the ERK1/2 and p38 MAPKs (Chen et al. 2006, Adya et al. 2008a,b). We therefore investigated the activation of these MAPKs by both visfatin and NMN. Treatment of cells with $200 \mathrm{ng} / \mathrm{ml}$ visfatin caused a significant $122 \%$ up-regulation in ERK1/2 phosphorylation after $15 \mathrm{~min}$ $(P<0 \cdot 001$; Fig. 3$)$. This result was mirrored by a similar 15-min increase in ERK1/2 phosphorylation of $105 \%$ by NMN $(P<0 \cdot 001$; Fig. 3). Co-incubation with the specific visfatin inhibitor FK866 significantly reduced ERK1/2 activation by visfatin compared to visfatin alone $(P<0.05$; Fig. 3). Neither visfatin nor NMN caused any significant change in p38 activation compared to basal (Fig. 3). PMA positive control showed an expected significant increase in both p38 and ERK1/2 MAPK activation.

\section{Discussion}

Despite significant interest and controversy over the effects of visfatin and insulin receptor signalling, there have been relatively little data published which have suggested precisely what the biological functions of visfatin are, and more importantly, how these functions might fit into the models of metabolic disorder. Here, we can report for the first time that visfatin is able to regulate the mRNA expression of a variety of genes which are key to maintaining normal pancreatic $\beta$-cell function. We found that 12 of the 84 genes tested were significantly up- or down-regulated by treatment with $50 \mathrm{ng} / \mathrm{ml}$ visfatin (a concentration only slightly higher than that reported in the circulation of obese/diabetic subjects (Chen et al. 2006); Table 1), including insulin and syntaxin 4 (a protein known to facilitate glucosestimulated insulin secretion (Spurlin \& Thurmond 2005)). We have subsequently confirmed visfatin regulation of mRNA expression of several of these genes using a separate real-time PCR using prevalidated primers (Supplementary Figure). Previously published reports have highlighted the importance of these genes in $\beta$-cell function, particularly hepatocyte nuclear factor (HNF) $4 \alpha$ and HNF1 $\beta$ (Maestro et al. 2007), two genes which form single gene defects in forms of maturity onset diabetes of the young (MODY1 and MODY5 respectively). The marked up-regulation of these important transcription factors fits well with the observation here that visfatin causes an increase in insulin secretion (Fig. 2), as they are both thought to be involved in insulin gene transcription (Bernardo et al. 2008).

Significant increases were also observed in some unexpected genes, including CD28 (a 97-fold increase). CD28 is more commonly associated with type 1 diabetes and immune responses, and any potential role in T2D is still unclear. The increase we report in nuclear factor- $\mathrm{kB}$ $(\mathrm{NF}-\kappa \mathrm{B})$ fits well with previously published data regarding visfatin and NF- $\mathrm{B}$ activity in endothelial cells (Adya et al. 2008a,b). Visfatin has previously been suggested to have a role in the regulation of insulin secretion, where NMN was shown to be able to rescue 

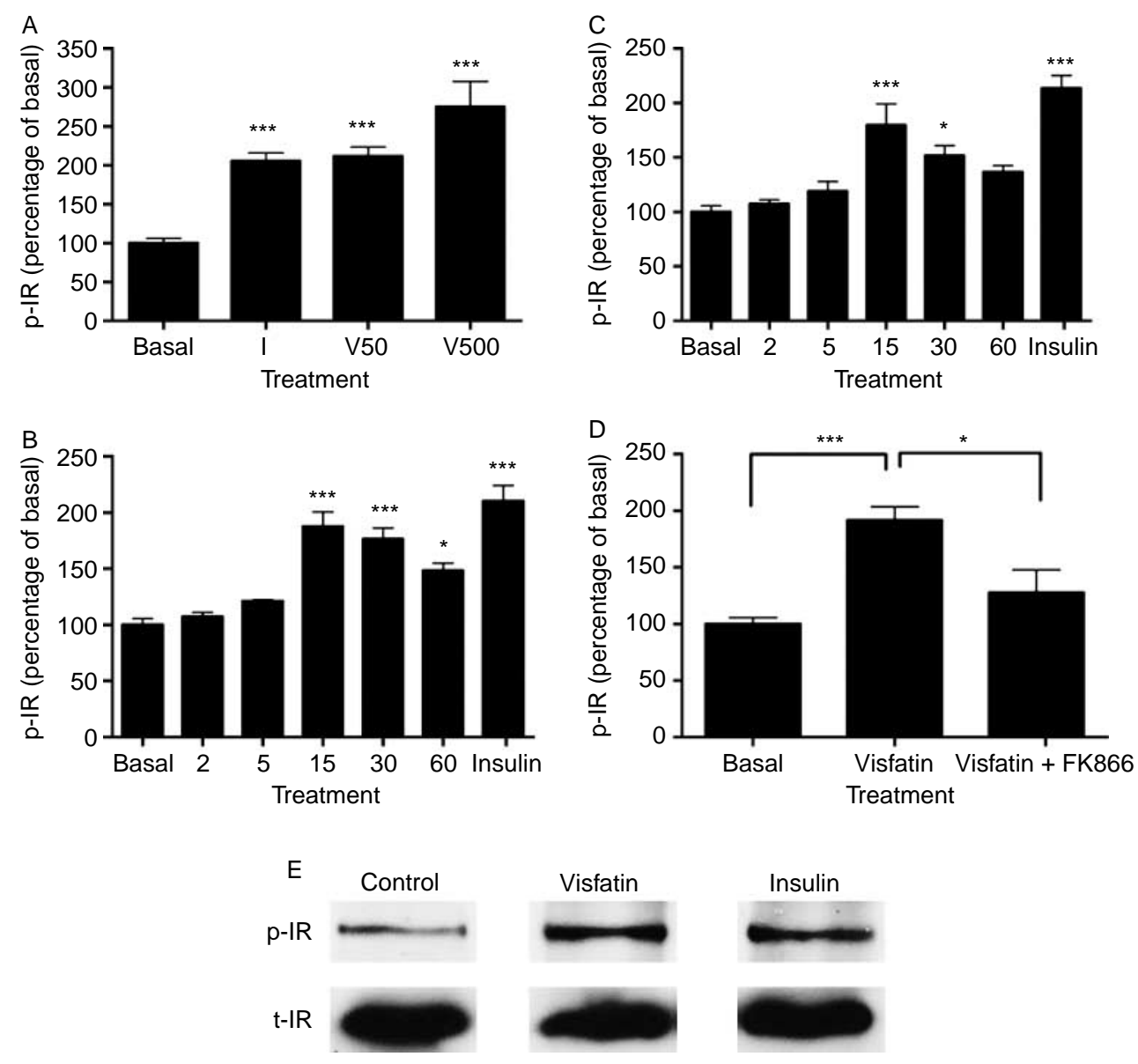

Figure 2 Phospho-specific analysis of insulin receptor activation. (A) Visfatin (50 and $500 \mathrm{ng} / \mathrm{ml}$ ) caused significant $104 \%(P<0.001)$ and $178 \%(P<0.001)$ increases in insulin receptor phosphorylation respectively. This was confirmed by phospho-specific western blotting (data not shown). $I=100 \mathrm{nM}$ insulin-positive control, $n=4$. (B) Time-dependent analysis of insulin receptor phosphorylation (using $200 \mathrm{ng} / \mathrm{ml}$ visfatin) showed that a significant $(P<0.001)$ activation of the insulin receptor compared to basal occurred after $15 \mathrm{~min}$, and remained significantly higher than basal for $60 \mathrm{~min}(P<0.05)$.

(C) Incubation with $100 \mu \mathrm{M}$ NMN also caused a significant increase in insulin receptor phosphorylation $(P<0.01)$ after $15 \mathrm{~min}$ in these cells, $n=4$. (D) During co-incubation of visfatin $(200 \mathrm{ng} / \mathrm{ml})$ and $10 \mathrm{nM}$ FK866, significantly less insulin receptor phosphorylation was seen than that seen with visfatin treatment alone $(P<0 \cdot 05)$. (E) Western blot images for phospho-insulin receptor $(\mathrm{p}-\mathrm{IR})$ and total insulin receptor $(\mathrm{t}-\mathrm{IR})$ in cells treated with $200 \mathrm{ng} / \mathrm{ml}$ visfatin and $100 \mathrm{nM}$ insulin as positive controls. Images are representative of four independent experiments.

insulin secretion in islets isolated from visfatin knockout mice (Revollo et al. 2007). This report, however, focussed on the intracellular actions of visfatin, as opposed to administered visfatin. Our observations suggest that visfatin therefore has an important role as both an intra- and an extracellular regulator of pancreatic $\beta$-cell function.

Interestingly, the significant increase in insulin secretion from BTC cells seen here was blocked by co-incubation with the specific NAMPT inhibitor FK866 (Fig. 1). This might initially suggest that the mechanism by which visfatin is regulating insulin secretion is through its ability to synthesize NMN (as FK866 noncompetitively binds the enzymatic region of visfatin which normally binds nicotinamide; Kim et al. 2006). However, NMN itself did not significantly increase insulin secretion in the BTC cells, suggesting a more complex mechanism for this action of visfatin. It is possible that FK866 not only blocks the ability of visfatin to bind nicotinamide, but also blocks other as yet undescribed interactions, possibly those involving the insulin receptor. Clearly, further research is needed to fully assess the physiological relevance of these observations.

Curiously, we found that at a supraphysiological concentration $(500 \mathrm{ng} / \mathrm{ml})$ of visfatin caused a decrease in cell viability over $24 \mathrm{~h}$ (data not shown). Although most reports of the circulating levels of 

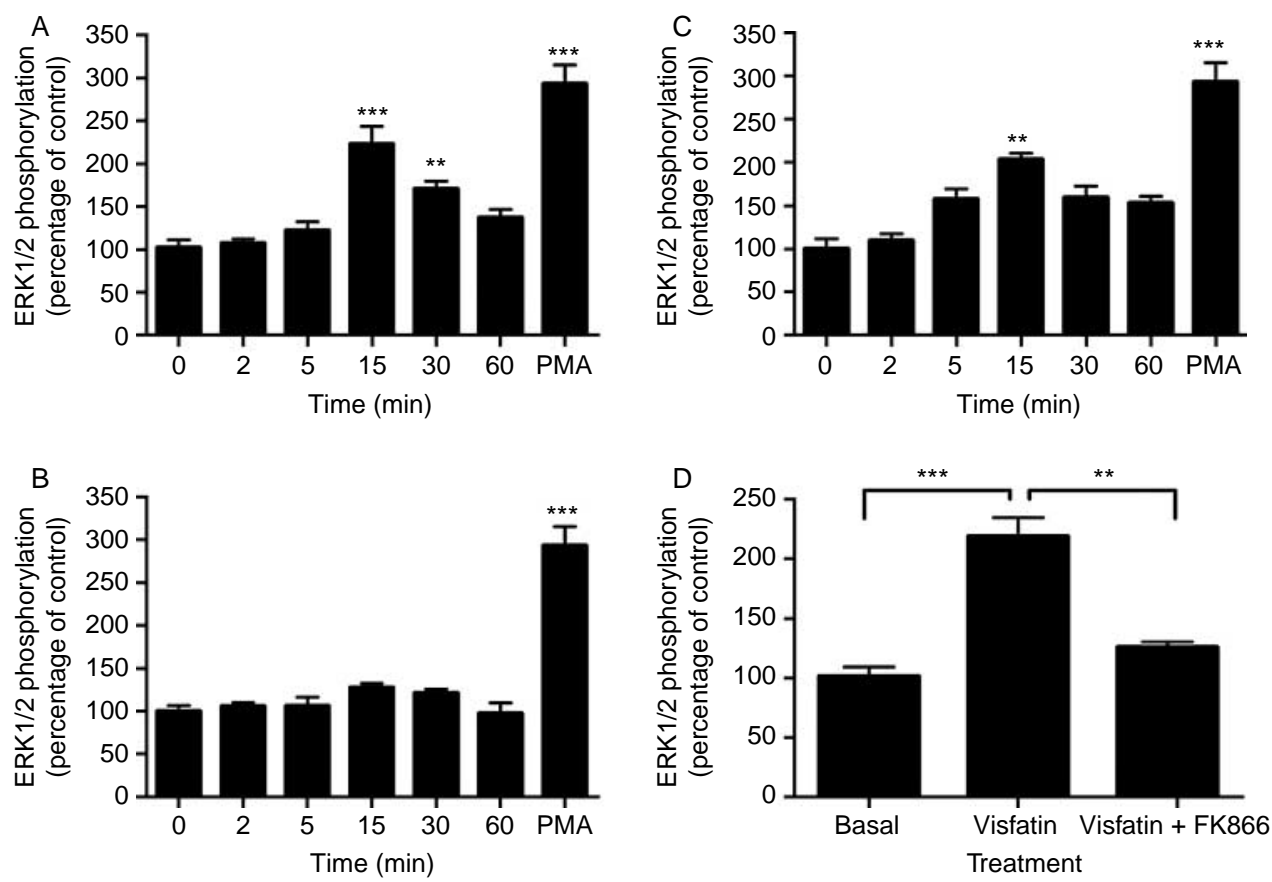

Figure 3 Analysis of MAPK activation by visfatin. The effect of visfatin/NMN on MAPK activation was measured using a phospho-specific ERK1/2 cell-based assay. (A) Visfatin ( $200 \mathrm{ng} / \mathrm{ml})$ treatment resulted in a significant $130 \%$ up-regulation of ERK $1 / 2$ phosphorylation after $15 \mathrm{~min}$ compared to basal $(P<0 \cdot 001)$. (D) Co-incubation with $10 \mathrm{nM}$ FK866 significantly inhibited this ERK1/2 activation $(P<0 \cdot 01)$. (B) No significant effect of $200 \mathrm{ng} / \mathrm{ml}$ visfatin was seen on p38 activation compared to basal. (C) Incubation of BTC with $100 \mu \mathrm{M}$ NMN also caused a significant increase of $105 \%$ after $15 \min (P<0.001)$.

visfatin are well below this concentration, some have suggested far higher circulating concentrations of visfatin, potentially placing this within the physiological range (Chan et al. 2007), which suggests that visfatin may have a more complex role in the pancreas than our data suggest. One previous report has linked $\beta$-cell dysfunction to elevated serum visfatin levels (LopezBermejo et al. 2006), and the potential exists that although a short-term increase in insulin secretion is seen, longer term effects of exposure to elevated visfatin might be more deleterious to the $\beta$-cell.

The role of visfatin in insulin receptor signalling is a controversial one. We report for the first time that in the pancreatic $\beta$-cell, visfatin has a definite role in insulin receptor signalling, with a significant up-regulation of insulin receptor phosphorylation occurring when BTC cells are exposed to a range of visfatin concentrations. This matches previous reports of an interaction of visfatin with the insulin signalling pathway in at least one other tissue (Xie et al. 2007). As insulin signalling has been shown to be essential for $\beta$-cell function (Otani et al. 2004), this confirms the importance of this role for visfatin in the pancreas, a role which exists potentially via multiple mechanisms (both intra- and extracellular) involving both insulin secretion and signalling.
In conclusion, these data suggest that visfatin has a role in multiple aspects of pancreatic $\beta$-cell biology, including a role in the regulation of insulin secretion and receptor signalling. These findings confirm the previously reported modulatory role of visfatin in the insulin signalling pathway, and suggest that these actions occur via its ability to synthesize NMN.

\section{Supplementary data}

This is linked to the online version of the paper at http://dx.doi.org/ 10.1677/JME-09-0071.

\section{Declaration of interest}

The authors declare that there is no conflict of interest that could be perceived as prejudicing the impartiality of the research reported.

\section{Funding}

This research was partly funded by an Early Research Award Scheme (University of Wolverhampton). 


\section{References}

Adya R, Tan BK, Chen J \& Randeva HS $2008 a$ Nuclear factor- $\kappa$ B induction by visfatin in human vascular endothelial cells. Diabetes Care 31 758-760.

Adya R, Tan BK, Punn A, Chen J \& Randeva HS 2008 $b$ Visfatin induces human endothelial VEGF and MMP-2/9 production via MAPK and PI3K/Akt signalling pathways: novel insights into visfatin-induced angiogenesis. Cardiovascular Research 78 356-365.

Ahima RS 2006 Adipose tissue as an endocrine organ. Obesity 14 242S-249S.

Astrup A \& Finer N 2000 Redefining type 2 diabetes: 'diabesity' or 'obesity dependent diabetes mellitus'? Obesity Reviews 1 57-59.

Bernardo AS, Hay CW \& Docherty K 2008 Pancreatic transcription factors and their role in the birth, life and survival of the pancreatic beta cell. Molecular and Cellular Endocrinology 294 1-9.

Berndt J, Kloting N, Kralisch S, Kovacs P, Fasshauer M, Schon MR, Stumvoll M \& Bluher M 2005 Plasma visfatin concentrations and fat depot-specific mRNA expression in humans. Diabetes 54 2911-2916.

Brown JE, Thomas S, Digby JE \& Dunmore SJ 2002 Glucose induces and leptin decreases expression of uncoupling protein-2 mRNA in human islets. FEBS Letters 513 189-192.

Brown JE, Onyango DJ \& Dunmore SJ 2007 Resistin down-regulates insulin receptor expression, and modulates cell viability in rodent pancreatic beta-cells. FEBS Letters 581 3273-3276.

Chan TF, Chen YL, Chen HH, Lee CH, Jong SB \& Tsai EM 2007 Increased plasma visfatin concentrations in women with polycystic ovary syndrome. Fertility and Sterility 88 401-405.

Chen MP, Chung FM, Chang DM, Tsai JC, Huang HF, Shin SJ \& Lee YJ 2006 Elevated plasma level of visfatin/pre-B cell colony-enhancing factor in patients with type 2 diabetes mellitus. Journal of Clinical Endocrinology and Metabolism 91 295-299.

Jin H, Jiang B, Tang J, Lu W, Wang W, Zhou L, Shang W, Li F, Ma Q, Yang Yet al. 2008 Serum visfatin concentrations in obese adolescents and its correlation with age and high-density lipoprotein cholesterol. Diabetes Research and Clinical Practice 79 412-418.

Kim MK, Lee JH, Kim H, Park SJ, Kim SH, Kang GB, Lee YS, Kim JB, Kim KK, Suh SW et al. 2006 Crystal structure of visfatin/pre-B cell colony-enhancing factor 1 /nicotinamide phosphoribosyltransferase, free and in complex with the anti-cancer agent FK-866. Journal of Molecular Biology 362 66-77.
Kim SR, Bae SK, Choi KS, Park SY, Jun HO, Lee JY, Jang HO, Yun I, Yoon KH, Kim YJ et al. 2007 Visfatin promotes angiogenesis by activation of extracellular signal-regulated kinase $1 / 2$. Biochemical and Biophysical Research Communications 357 150-156.

Li L, Yang G, Li Q, Tang Y, Yang M, Yang H \& Li K 2006 Changes and relations of circulating visfatin, apelin, and resistin levels in normal, impaired glucose tolerance, and type 2 diabetic subjects. Experimental and Clinical Endocrinology and Diabetes 114 544-548.

Lopez-Bermejo A, Chico-Julia B, Fernandez-Balsells M, Recasens M, Esteve E, Casamitjana R, Ricart W \& Fernandez-Real JM 2006 Serum visfatin increases with progressive beta-cell deterioration. Diabetes $\mathbf{5 5}$ 2871-2875.

Maestro MA, Cardalda C, Boj SF, Luco RF, Servitja JM \& Ferrer J 2007 Distinct roles of HNF1beta, HNFlalpha, and HNF4alpha in regulating pancreas development, beta-cell function and growth. Endocrine Development 12 33-45.

Muller D, Huang GC, Amiel S, Jones PM \& Persaud SJ 2006 Identification of insulin signaling elements in human beta-cells: autocrine regulation of insulin gene expression. Diabetes $\mathbf{5 5}$ 2835-2842.

Otani K, Kulkarni RN, Baldwin AC, Krutzfeldt J, Ueki K, Stoffel M, Kahn CR \& Polonsky KS 2004 Reduced beta-cell mass and altered glucose sensing impair insulin-secretory function in betaIRKO mice. American Journal of Physiology. Endocrinology and Metabolism 286 E41-E49.

Revollo JR, Korner A, Mills KF, Satoh A, Wang T, Garten A, Dasgupta B, Sasaki Y, Wolberger C, Townsend RR et al. 2007 Nampt/PBEF/ Visfatin regulates insulin secretion in beta cells as a systemic NAD biosynthetic enzyme. Cell Metabolism 6 363-375.

Spurlin BA \& Thurmond DC 2005 Syntaxin 4 facilitates biphasic glucose-stimulated insulin secretion from pancreatic $\beta$-cells. Molecular Endocrinology 20 183-193.

Trayhurn P \& Wood IS 2005 Signalling role of adipose tissue: adipokines and inflammation in obesity. Biochemical Society Transactions 33 1078-1081.

Xie H, Tang SY, Luo XH, Huang J, Cui RR, Yuan LQ, Zhou HD, Wu XP \& Liao EY 2007 Insulin-like effects of visfatin on human osteoblasts. Calcified Tissue International 80 201-210.

Received in final form 12 October 2009

Accepted 11 November 2009

Made available online as an Accepted Preprint 11 November 2009 